\title{
THE DIFFERENTIAL RESPONSE OF THE ADRENAL CORTEX AND MEDULLA TO BACTERIAL ENDOTOXIN *
}

\author{
BY RICHARD H. EGDAHL $\dagger$ \\ (From the Department of Surgery and the Surgical Research Laboratories, Medical College of \\ Virginia, Richmond, Va.)
}

(Submitted for publication November 25, 1958; accepted March 3, 1959)

The administration of bacterial endotoxin to an animal results in a characteristic series of events, including hypotension, hyperglycemia, changes in the white cells and, at high dosage levels, death (1). The mechanism by which endotoxin produces these effects has not been defined and search for a common mode of action has not yet been fruitful. However, it has been noted on several occasions that there are many similarities between the systemic effects of endotoxin and epinephrine. It has therefore been speculated that some, if not most, of the effects of endotoxin are due to a liberation of epinephrine resulting from endotoxin stimulation of the adrenal medulla.

Since there is little evidence available to prove or disprove this concept, the present studies were set up to determine the effect of bacterial endotoxin on adrenal medullary function. It was thought desirable to use a technique whereby samples of adrenal venous blood could be obtained and analyzed for catechol amines noting the response to various dosages of endotoxin. This would provide a more direct measurement of adrenal medullary function than the determination of peripheral blood levels of the medullary hormones. In addition to determining the adrenal venous output per minute of catechol amines, measurements of the output of 17-hydroxycorticosteroids were made in order to contrast adrenal cortical and medullary responses. Similar experiments were performed in animals with spinal cord transections to provide information concerning the pathways by which adrenal cortical and medullary activation took place.

\section{MATERIAL AND METHODS}

Healthy adult mongrel dogs ranging in weight from 10 to $18 \mathrm{Kg}$. were used in these experiments. Cannulations of the lumbo-adrenal vein were carried out accord-

\footnotetext{
* These studies were partially supported by USPHS Grant No. A-2267.

$\dagger$ Markle Scholar in Medical Sciences.
}

ing to the technique of Hume and Nelson (2). This technique allows intermittent collection of adrenal venous blood to be made in the unanesthetized, unstimulated animal. Spinal cord transection was performed in four animals through a dorsal midline incision. Transection of the spinal cord between C-7 and T-1 was accomplished with a wire loop. Blood pressures were maintained in the immediate post-transection period by the intramuscular injection of Neo-Synephrine. Spinal cord sectioned animals were maintained in the postoperative period by the intravenous administration of $500 \mathrm{ml}$. of 5 per cent dextrose in saline on each of the first two postoperative days, followed by food and water ad libitum after that. The animals were supported in a sling during portions of the day and this allowed them to take food and water without assistance. Antibiotics consisting of penicillin, 200,000 units per day, and streptomycin, 200 mg. per day, were given intramuscularly and the animals were turned frequently in the first few days following surgery. With adequate attention to details it was possible to keep cord sectioned animals in good condition with little loss in weight and vigor.

The day after adrenal vein cannulation, dogs were placed on a laboratory table and control samples of adrenal venous blood were taken. Rectal temperatures were obtained throughout the course of the experiments by means of thermistors inserted at least three inches into the rectum. It has previously been found that Nembutal ${ }^{\circledR}$ markedly depresses the secretion of epinephrine in response to a variety of stimuli and for this reason animals were unanesthetized. Careful selection of animals for these experiments was necessary so that they would not be excitable and they were conditioned to the presence of laboratory workers and the attention of laboratory personnel coincident with obtaining frequent samples of adrenal venous blood. Usually the head of the dog was covered with a sheet to reduce apprehension as a result of environmental activity and an attendant stayed with the dog to pet him if signs of restlessness occurred. In the first few minutes of sample collections, occasional high values for catechol amines were observed, but most animals returned to basal levels and stayed there for long periods if unstimulated.

Purified endotoxin of the Boivin type derived from E. coli was prepared by the method of Spink and Anderson (3)..$^{1}$ Endotoxin solutions were made up so as to contain $0.1 \mathrm{mg}$. per $\mathrm{ml}$. of saline and all endotoxin injections were given intravenously in a period of approxi-

1 Obtained through the courtesy of W. W. Spink and J. C. Melby. 
TABLE I

Output per minute of $E-N E$ from right adrenal gland after endotoxin administration *

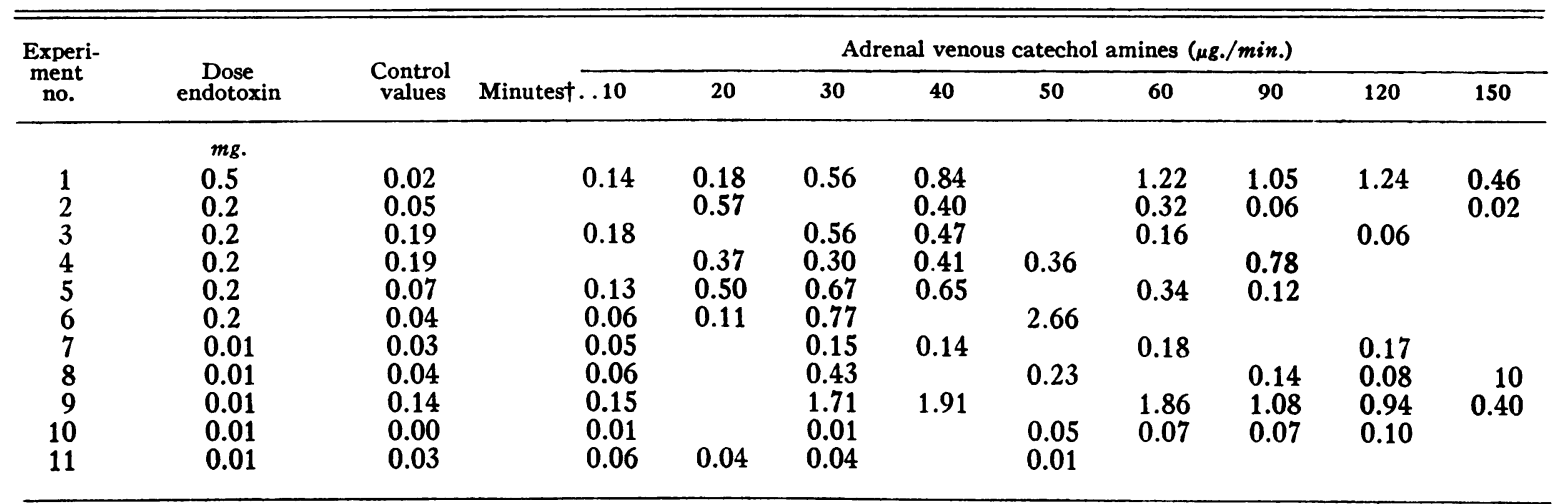

* All animals developed from 1 to $3^{\circ} \mathrm{C}$. fever within two hours after endotoxin.

$\dagger$ Time after endotoxin administration.

mately 10 seconds. In general, two schedules of dosages were used, one of $0.01 \mathrm{mg}$., the other of $0.2 \mathrm{mg}$. It had previously been found that $0.01 \mathrm{mg}$. elicited an adrenal cortical response, fever and hypotension without death and $0.2 \mathrm{mg}$. represented the maximal tolerated dose without a fatality rate of over 10 per cent in normal dogs.

Epinephrine and norepinephrine determinations were carried out by a modification (4) of the method of WeilMalherbe and Bone (5). Values are expressed in the results as total catechol amines (E-NE) although separate epinephrine and norepinephrine determinations were performed. This is because dihydroxyphenylethylamine and dihydroxyphenylalanine form fluorescent products with the methods used and therefore it is most accurate to report changes in total catechol amines. However, most of the increase in catechol amine output that took place was due to the epinephrine component, as measured. 17-Hydroxycorticosteroid determinations were performed according to the method of Nelson and Samuels (6). In some of the experiments, after one to two hours a dose of 25 units of corticotropin was given intravenously, following which more samples were obtained. Adrenal cannulation was carried out from one to 21 days after cord section and in all experiments endotoxin was administered on the day after adrenal vein cannulation. Blood pressure determinations were carried out in some experiments with an arterial polyethylene catheter connected to a mercury manometer.

\section{RESULTS}

A preliminary set of experiments was carried out in which only adrenal venous epinephrine and norepinephrine outputs (E-NE) were obtained following endotoxin administration. Reference to Table I indicates the pattern of response in these animals. Eleven dogs were given endotoxin at a dosage range from $0.01 \mathrm{mg}$. to $0.5 \mathrm{mg}$. All these animals manifested a fever of greater than $1.0^{\circ} \mathrm{C}$. two hours after endotoxin administration. There was no correlation between the degree of body temperature elevation and dosage of endotoxin administered. In Experiment 1, the animal was given $0.5 \mathrm{mg}$. of endotoxin and demonstrated a significant E-NE response at 30 minutes, followed by increasing secretion up to one hour after endotoxin administration and then return towards normal after two and one-half hours.

Five animals given $0.2 \mathrm{mg}$. of endotoxin responded with a significant increase of E-NE output, with maximal levels 20 to 30 minutes after drug administration. Two of five dogs given 0.01 mg. of endotoxin had a significant adrenal medullary response, with Dog No. 9 attaining levels as high as $1.91 \mu \mathrm{g}$. per minute 40 minutes after endotoxin. Corticotropin given during declining E-NE levels did not stimulate the adrenal medulla.

A second set of experiments was then carried out in which 17-hydroxycorticosteroids were determined in addition to the catechol amines and these results are shown in Table II.

Dosages in this group of experiments range from $0.01 \mathrm{mg}$. to $0.5 \mathrm{mg}$. and all animals demonstrated fevers of over $1.0^{\circ} \mathrm{C}$. In addition, all animals manifested maximal adrenal cortical stimulation as demonstrated by failure to increase corticosteroid output by corticotropin administration. In Experiment 1A, at a dosage of $0.01 \mathrm{mg}$. of endotoxin, when maximal adrenal cortical stimulation and fever occurred, there was no increase of catechol amine secretion. Similar results were ob- 
TABLE II

Output per minute of $E-N E$ and 17-OH from right adrenal gland after endotoxin administration *

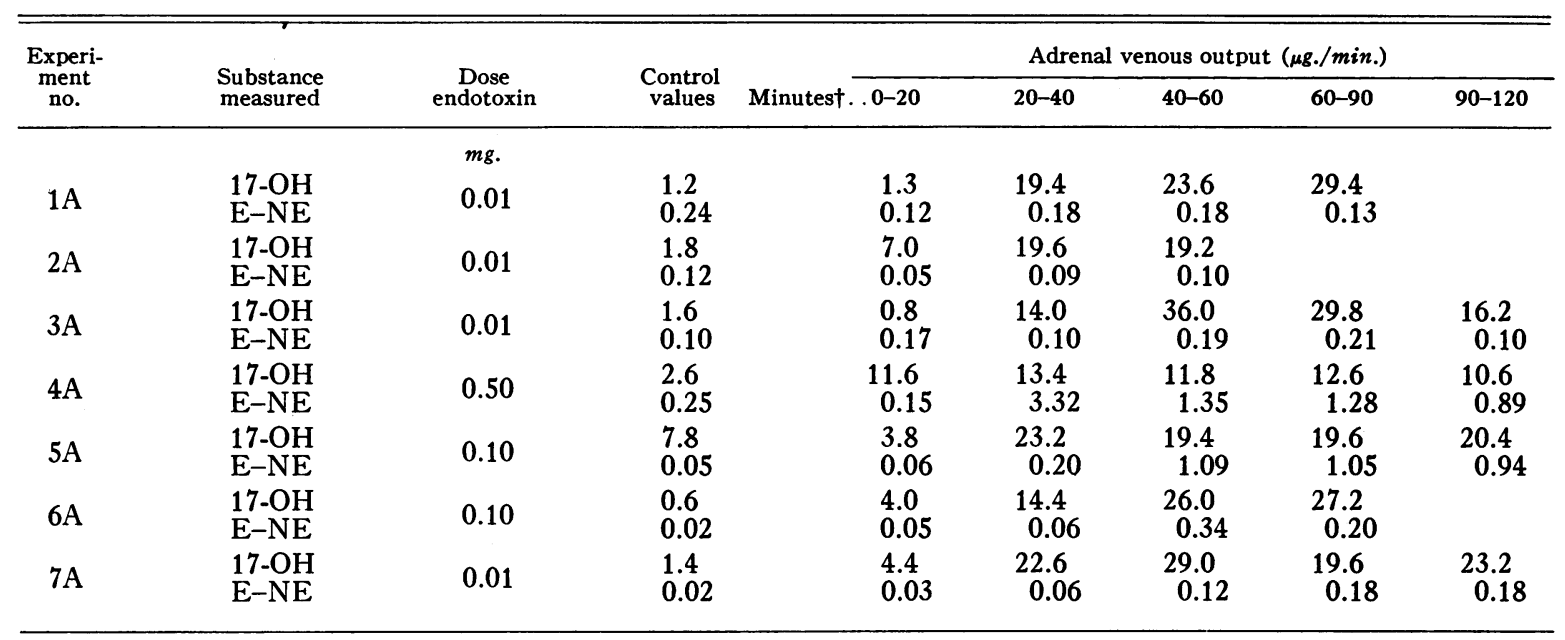

* In several of the experiments, the administration of 25 units of ACTH had no effect on E-NE levels and did not cause a further increase in 17-OH after endotoxin. All animals developed fever of 1 to $3^{\circ} \mathrm{C}$. after endotoxin.

$\dagger$ Time after endotoxin administration.

tained in Experiments 2A, 3A and 7A all of which involved the intravenous administration of 0.01 mg. of endotoxin. These experiments demonstrate clearly that a dose of endotoxin which uniformly results in the production of fever and maximal adrenal cortical stimulation may fail to result in adrenal medullary stimulation in addition. Experiments $4 \mathrm{~A}, 5 \mathrm{~A}$ and $6 \mathrm{~A}$ using doses of $0.1 \mathrm{mg}$. or more led to significant E-NE output increases. Throughout this set of experiments exogenous corticotropin did not further increase the output of 17-hydroxycorticosteroids which followed endotoxin stimulation.

Reference to Table III indicates the results of experiments in which dogs with spinal cord section and adrenal cannulae were given small and large doses of endotoxin. All animals with spinal cord transection responded with the expected maximal output of 17 hydroxycorticosteroids and with a fever of over $1.0^{\circ} \mathrm{C}$. at one and one-half hours following endotoxin administration. In contrast to the fever and adrenal cortical responses, none of the dogs responded to $0.01 \mathrm{mg}$. of endotoxin with an increase in $\mathrm{E}-\mathrm{NE}$ and another injection at 90 minutes of $0.2 \mathrm{mg}$. failed to alter adrenal medullary output of catechol amines from basal levels. Cord sectioned dogs given $0.2 \mathrm{mg}$. of endotoxin become hypotensive as do normal animals. Reference to Figure 1 indicates that even with a dose of endotoxin which consistently produced adrenal medullary stimulation in normal dogs (Figure 2), there was no response in the cord sectioned animals. One cord sectioned animal is not included on the protocol because he

TABLE III

Output per minute of $E-N E$ and 17-OH from right adrenal gland after endotoxin in cord sectioned dogs *

\begin{tabular}{|c|c|c|c|c|c|c|c|c|c|c|c|c|c|c|c|c|c|c|}
\hline \multirow{2}{*}{$\begin{array}{c}\text { Experi- } \\
\text { ment } \\
\text { no. }\end{array}$} & \multirow{2}{*}{$\begin{array}{c}\text { Sub- } \\
\text { stance } \\
\text { measured }\end{array}$} & \multirow{2}{*}{$\begin{array}{l}\text { Dose } \\
\text { endo- } \\
\text { toxin }\end{array}$} & \multirow{2}{*}{$\begin{array}{l}\text { Control } \\
\text { values }\end{array}$} & \multirow[b]{2}{*}{ Minutes $†$} & \multicolumn{14}{|c|}{ Adrenal venous output ( $\mu g . / \min )}$. \\
\hline & & & & & .10 & 20 & 30 & 40 & 50 & 60 & 75 & 90 & 105 & 120 & 150 & 180 & 210 & 240 \\
\hline & & mg. & & & & & & & & & & & & & & & & \\
\hline 1B & $\begin{array}{l}\text { 17-OH } \\
\text { E-NE }\end{array}$ & 0.01 & $\begin{array}{l}0.7 \\
0.02\end{array}$ & & $\begin{array}{l}2.8 \\
0.02\end{array}$ & & $\begin{array}{l}6.8 \\
0.05\end{array}$ & $\begin{array}{c}13.1 \\
0.03\end{array}$ & & & $\begin{array}{c}14.1 \\
0.05\end{array}$ & $\ddagger$ & $\begin{array}{c}25.0 \\
0.01\end{array}$ & $\begin{array}{c}26.4 \\
0.04\end{array}$ & $\begin{array}{c}22.9 \\
0.01\end{array}$ & $\begin{array}{c}21.8 \\
0.02\end{array}$ & $\begin{array}{c}18.4 \\
0.02\end{array}$ & $\begin{array}{c}21.7 \\
0.02\end{array}$ \\
\hline 2B & $\begin{array}{l}\text { 17-OH } \\
\text { E-NE }\end{array}$ & 0.01 & $\begin{array}{l}0.02 \\
0.00\end{array}$ & & & $\begin{array}{l}7.3 \\
0.01\end{array}$ & $\begin{array}{c}143 \\
0.00\end{array}$ & $\begin{array}{l}17.7 \\
0.01\end{array}$ & & $\begin{array}{c}15.0 \\
0.02\end{array}$ & $\begin{array}{c}14.5 \\
0.02\end{array}$ & $\ddagger$ & $\begin{array}{c}11.2 \\
0.01\end{array}$ & $\begin{array}{c}10.5 \\
0.02\end{array}$ & $\begin{array}{c}14.0 \\
0.01\end{array}$ & $\begin{array}{c}12.1 \\
0.01\end{array}$ & 0.01 & $\begin{array}{c}12.9 \\
0.01\end{array}$ \\
\hline $3 B$ & $\begin{array}{l}\text { 17-OH } \\
\text { E-NE }\end{array}$ & 0.20 & $\begin{array}{l}3.0 \\
0.08\end{array}$ & & & $\begin{array}{c}17.8 \\
0.12\end{array}$ & $\begin{array}{c}16.8 \\
0.13\end{array}$ & & $\begin{array}{c}11.0 \\
0.08\end{array}$ & $\begin{array}{c}12.6 \\
0.08\end{array}$ & $\begin{array}{l}9.4 \\
0.06\end{array}$ & $\begin{array}{l}18.1 \\
0.06\end{array}$ & & & $\begin{array}{c}16.2 \\
0.03\end{array}$ & & & \\
\hline
\end{tabular}

* The rectal temperature of all three dogs rose at least $1^{\circ} \mathrm{C}$. after endotoxin.

$\dagger$ Time af ter endotoxin administration.

$\ddagger 0.2 \mathrm{mg}$. endotoxin I.V. 
died following the injection of $0.2 \mathrm{mg}$. of endotoxin. Two of the other cord sectioned animals became very sick, with vomiting and hypotension following $0.01 \mathrm{mg}$. of endotoxin and it must be concluded that spinal sectioned animals are more sensitive than normal animals to these effects of endotoxin administration.

\section{DISCUSSION}

It is possible, without considering the data presented in this report, to make out quite a convincing case for the participation of epinephrine in the systemic response to bacterial endotoxin. Endotoxin sensitizes blood vessels to the action of epinephrine and norepinephrine (7). Intradermal injection of epinephrine in rabbits either preceded or followed by intravenous endotoxin yields an area of hemorrhagic necrosis where epinephrine was injected (8). Treatment with adrenolytic substances such as dibenamine prevents the vascular response of rabbits to typhoid endotoxin (9). Boquet and Izard conclude that endotoxin leads to the liberation of epinephrine or epinephrinelike substances which themselves lead to peripheral vasoconstriction. Adrenolytic agents should therefore prevent the blood vessel constriction which occurs following endotoxin administration. Feldman and Gellhorn (10) suggest that fever and hyperglycemia following endotoxin administration are due to stimulation of the sympathico-

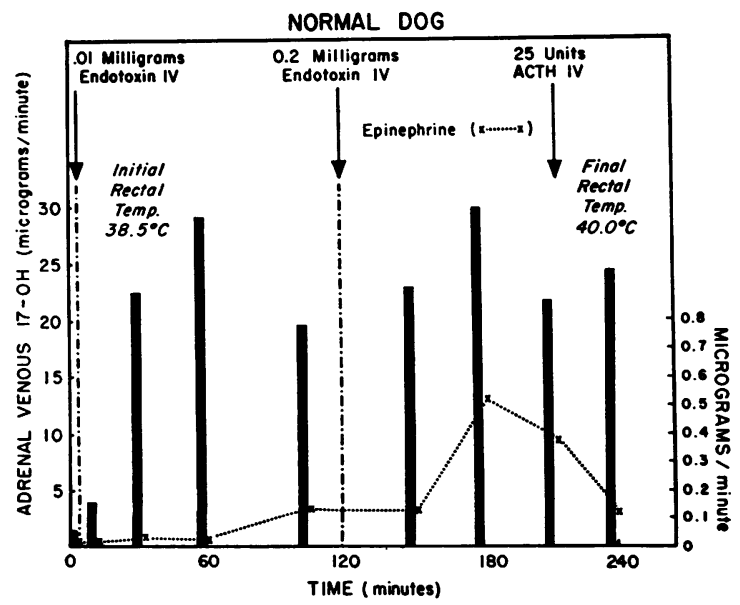

Fig. 1. Dog with Spinal Cord Transection at C-7 Given 0.01 and 0.2 of Endotoxin IntraveNOUSLY

There is no epinephrine response in this animal to either the small or large dose of endotoxin, although increased adrenal cortical secretion and fever occur.

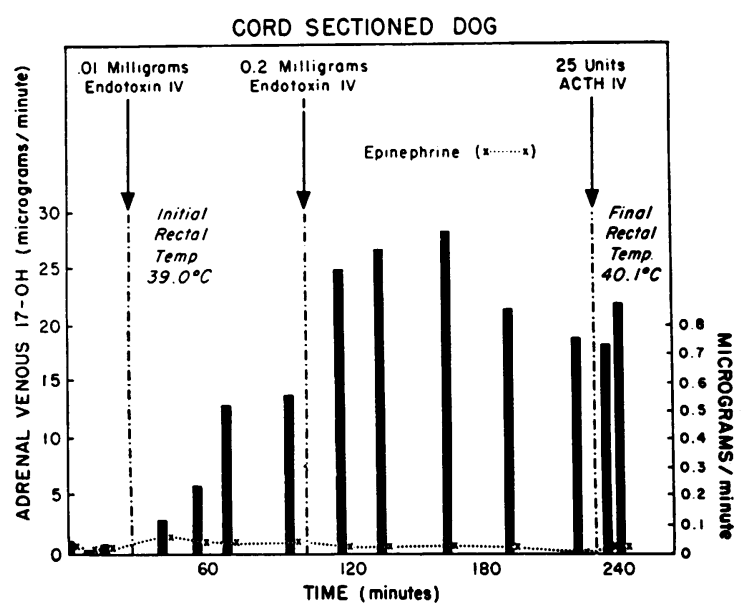

Fig. 2. Normal Dog Given 0.01 mg. Endotoxin Intravenously, Followed by 0.2 mg. Two Hours Later

Note significant epinephrine response following the larger dose of endotoxin.

adrenal system. In a recent article Thomas, Zweifach and Benacerraf (11) emphasized the possible role of epinephrine in mediating endotoxin effects and they mentioned the further possibility that endotoxin lesions may be due to serotonin.

There are few previous studies related to the problem of adrenal medullary secretion following endotoxin administration. Cannon and Pereira (12) demonstrated that the administration of typhoid bacilli to adrenal-demedullated animals resulted in a different series of events than in animals with normal adrenals. Adrenal-demedullated animals demonstrate a slow secondary rise in temperature in contrast to the biphasic response of the normal animals. Removal of the adrenal medulla rendered the animals more susceptible to the lethal effect of bacterial endotoxin and the above-mentioned authors concluded that "the response of the adrenal medulla during toxic fevers is serviceable to the organism" (12).

Hoshi (13) claimed to have demonstrated increased circulating blood levels of epinephrine with a maximum response two to four hours after the injection of dysenteric toxin. He claims to have observed a depression in blood level of epinephrine following large quantities of the toxin. Blood sugars were measured in Hoshi's experiments and hyperglycemia occurred at the same time as did the increase in blood levels of epinephrine. More recently, Heiffer, Mundy and Grimm (14) have demonstrated that $E$. coli endotoxin given in lethal doses to rabbits resulted in unstatistical ele- 
vations in peripheral blood epinephrine levels. Norepinephrine levels were unchanged in the initial hypotensive period but were significantly elevated statistically five hours following endotoxin administration.

Our findings demonstrate quite clearly that the response of the adrenal medulla is dependent upon the dosage of endotoxin administered. One onehundredth mg. of endotoxin uniformly results in maximal adrenal cortical stimulation, as measured by the output per minute of 17 hydroxycorticosteroid. Such a dose gives a fever of over $1.0^{\circ}$ C. in 100 per cent of animals. In contrast, only two of eight normal animals in this study showed an increased secretion of E-NE following a dosage of $0.01 \mathrm{mg}$. of endotoxin. All animals demonstrated an adrenal medullary response to a dosage of $0.1 \mathrm{mg}$. or greater. Therefore, although it is possible that at higher dosage levels the endogenous release of epinephrine from the adrenal medulla accounts for some of the systemic results after bacterial endotoxin administration, the occurrence of these effects at lower dosage levels is not dependent upon epinephrine. It is interesting that the response of the adrenal medulla is one of the least sensitive indices of endotoxin activity, in contrast to the extreme sensitivity of the pituitary-adrenal axis.

Results of the experiments in the cord sectioned animals show that the mechanism of endotoxin action on the adrenal medulla at high dosage levels is not a direct one and that it is not a result of hypotension. If endotoxin passed via the blood stream to the adrenal medulla and directly stimulated the release of epinephrine and norepinephrine, spinal cord section should not alter this effect. The fact that no adrenal medullary output increase occurred in response to large doses of bacterial endotoxin in hypotensive cord sectioned animals indicates that nervous pathways are necessary to this response. It does not give evidence as to whether the essential nervous connections are afferent or efferent. It seems most likely, however, that endotoxin acts at some site in the central nervous system above the level of cord transection with stimulation of nerve fibers passing down the cord and out the splanchnic nerves which supply the adrenal medulla. That the adrenal cortical stimulating effect does not depend upon descending nerve pathways is shown by the maximal adrenocortical response to endotoxin administration seen in the cord sectioned animals. The great potency of intrathecally administered endotoxin in producing fever and other systemic responses has been emphasized by Keene (15), Bennett and Cluff (1) and others.

There appear to be several pathways by which stimulation of epinephrine release from the adrenal medulla may occur. von Euler (16) describes experiments in which splanchnic nerve stimulation, intravenously administered nicotine and histamine all result in high levels of peripheral blood epinephrine. Several investigators have described experiments involving central nervous system stimulation and its effect upon epinephrine release from the adrenal medulla. Centers exist in the cerebral cortex $(17,18)$ and hypothalamus (19) which both increase and decrease adrenal medullary epinephrine secretion and it is reported that ablation of the frontal cortex results in altered adrenal medullary secretion. Our studies indicate that the administration of endotoxin results in adrenal medullary stimulation as a result of a direct action on the central nervous system. Experiments in dogs with "isolated pituitary islands" indicate that the central nervous system center for epinephrine secretion is located in the high medulla or pons (20). The epinephrine center evidently acts on the adrenal medulla through descending nervous pathways in the spinal cord. Suzuki and co-workers (21) have described descending spinal pathways subserving epinephrine secretion from the adrenal following insulin hypoglycemia. Although at high dosage levels of endotoxin the endogenous secretion of epinephrine may contribute to the total systemic response following endotoxin administration, there can be no question that the fever and the adrenal cortical response, at least, are independent of adrenal medullary activation.

Our findings are not completely in accord with some of the previously reported studies on this subject. Chambers, Kọenig, Koenig and Windle (22) found that dogs with cord section at C-7 did not demonstrate fevers following the administration of pyromen. Keeton (23), however, found that although animals given typhoid vaccine failed to develop fever two to four days after cord section, if the period after transection were extended to three to seven days, fever did occur. In the 
present study it was found that dogs responded to endotoxin with fever as early as one day after cord transection and that this fever producing effect of endotoxin was still present as long as three weeks after cord transection.

\section{SUM MARY}

1. Small doses of E. coli endotoxin (0.01 mg.) administered intravenously to dogs result in maximal adrenal cortical stimulation and fever, but infrequently lead to increased adrenal medullary secretion.

2. Large doses of $E$. coli endotoxin $(0.2 \mathrm{mg}$.) administered intravenously to dogs result in adrenal medullary stimulation, in addition to the adrenal cortical stimulating and fever promoting activities.

3. Transection of the spinal cord at C-7 abolishes the adrenal medullary response to large doses of bacterial endotoxin, leaving unimpaired the febrile, hypotensive and adrenal cortical responses. It is suggested that adrenal medullary activation following endotoxin is dependent on descending nerve pathways in the spinal cord.

4. Epinephrine release is not necessary for the febrile and adrenocortical stimulating effects of endotoxin.

5. It is concluded that there is a differential response of the adrenal cortex and medulla to endotoxin, with the pituitary adrenal axis more sensitive than the central nervous system center which controls epinephrine release.

\section{REFERENCES}

1. Bennett, I. L., Jr., and Cluff, L. E. Bacterial pyrogens. Pharmacol. Rev. 1957, 9, 427.

2. Hume, D. M., and Nelson, D. H. Adrenal cortical function in surgical shock. Surg. Forum 1954, 5,568 .

3. Spink, W. W., and Anderson, D. Experimental studies on the significance of endotoxin in the pathogenesis of brucellosis. J. clin. Invest. 1954, $33,540$.

4. Aronow, L., Howard, F. A., and Wolff, D. Plasma epinephrine and norepinephrine content in mammals (abstract). J. Pharm. exp. Ther. 1956, 116, 1.

5. Weil-Malherbe, H., and Bone, A. D. The chemical estimation of adrenalin-like substances in blood. Biochem. J. 1952, 51, 311.

6. Nelson, D. H., and Samuels, L. T. A method for the determination of 17-hydroxycorticosteroids in blood: 17-Hydroxycorticosterone in the peripheral circulation. J. clin. Endocr. 1952, 12, 519.
7. Zweifach, B. W., Nagler, A. L., and Thomas, L. The role of epinephrine in the reactions produced by the endotoxins of gram-negative bacteria. II. The changes produced by endotoxin in the vascular reactivity to epinephrine, in the rat mesoappendix and the isolated, perfused rabbit ear. $\mathrm{J}$. exp. Med. 1956, 104, 881.

8. Thomas, L. The role of epinephrine in the reaction produced by the endotoxin of gram-negative bacteria. I. Hemorrhagic necrosis produced by epinephrine in the skin of endotoxin-treated rabbits. J. exp. Med. 1956, 104, 865.

9. Boquet, P., and Izard, Y. Effect of dibenamin on vascular response of rabbits to typhoid endotoxin. Proc. Soc. exp. Biol. (N. Y.) 1950, 75, 254.

10. Feldman, J., and Gellhorn, E. The influence of fever on the vago-insulin and sympathetico-adrenal systems. Endocrinology 1941, 29, 141.

11. Thomas, L., Zweifach, B. W., and Benacerraf, B. Mechanisms in the production of tissue damage and shock by endotoxin. Trans. Ass. Amer. Phycns 1957, 70, 54

12. Cannon, W. B., and Pereira, J. R. Increase of adrenal secretion in fever. Proc. nat. Acad. Sci. (Wash.) 1924, 10, 247.

13. Hoshi, N. Dysenteric venenation and adrenalin secretion. J. Orient. Med. 1933, 18, 17.

14. Heiffer, M. H., Mundy, R. L., and Grimm, L. J. E. Effect of bacterial lipopolysaccharides on plasma catechol amine levels. Fed. Proc. 1958, 17, 68.

15. Keene, W. R. The pathogenesis of fever. Fevers produced by intrathecal injection of endotoxin. Bull. Johns Hopk. Hosp. 1956, 99, 103.

16. von Euler, U. S. Catechol hormones in blood. Ciba Found. Coll. Endocr. 1957, 11, 379.

17. Ferguson, R. W., Folkow, B., Mitts, M. G., and Hoff, E. C. Effect of cortical stimulation upon epinephrine activity. J. Neurophysiol. 1957, 20, 329.

18. von Euler, U. S., and Folkow, B. The effect of stimulation of autonomic areas in the cerebral cortex upon the adrenaline and noradrenaline secretion from the adrenal gland in the cat. Acta physiol. scand. 1958, 42, 313.

19. Goldfien, A., and Ganong, W. F. Diencephalic areas affecting adrenal medullary secretion of epinephrine and norepinephrine. Fed. Proc. 1958, 17, 56.

20. Egdahl, R. H. Adrenal cortical and medullary response to trauma in dogs with isolated pituitaries. In preparation.

21. Suzuki, T., Tanaka, I., Ninagawa, C., Nakamura, T., and Fujisaki, S. Descending spinal pathway subserving the adrenaline secretion of the adrenal in dogs. Tôhoku J. exp. Med. 1958, 67, 293.

22. Chambers, W. W., Koenig, H., Koenig, R., and Windle, W. F. Site of action in the central nervous system of a bacterial pyrogen. Amer. J. Physiol. 1949, 159, 209.

23. Keeton, R. W. Vaccine fever in rabbits rendered poikilothermous by cervical cord transection. Amer. J. Physiol. 1924, 71, 120. 